\title{
Editorial:
}

\section{The Journal of Clinical and Scientific Research: The year that has gone by!}

A year ago, the Journal of Clinical and Scientific Research (JCSR) was born on the occasion of the Sri Venkateswara Institute of Medical Sciences (SVIMS) celebrating its $19^{\text {th }}$ Anniversary. ${ }^{1}$ The JCSR, is published quarterly, not only in the print format, but also in the "free full-text" format in the journal page of institute's website (http://svimstpt.ap.nic.in/jcsr/jhome.htm). The journal has attracted 81 submissions in its first year from across the country, has grown fast and has completed its first birthday! The journal is already indexed in Index Copernicus, Academic Index and Open J-Gate.

This peer-reviewed journal promotes electronic submission and fast-track processing with a submission to decision time of 3 months. This fast-track processing time and free-full text online presence will be a boon to young researchers who wish to publish their research work. The Medical Council of India in its Amendment Notification dated 9th December 2009 of the Postgraduate Medical Education Regulations, 2000, Clause 13 under the heading "Training Programme" added the following as Clause 13.9: "postgraduate students pursuing degree course in broad- as well as super-specialities would be required to present one poster presentation, to read one paper at a national/state conference and to present one research paper which should be published/accepted for publication/sent for publication during the period of his postgraduate studies so as to make him eligible to appear at the postgraduate degree examination". The JCSR encourages vibrant young faculty researchers and postgraduates to take advantage of the fasttrack processing mechanism and submit their work for publication in the journal.

From 2013, in addition to the online and print versions, the JCSR is also bringing out a CD-version of the journal to facilitate dissemination of the content to places with poor internet connectivity. Other innovations scheduled for 2013 include the introduction of sections "Journal Scan" and "Short Report" among others. We hope that these innovations will enthuse all researchers and sincerely hope that the best research gets published in the JCSR!

B. Vengamma

Hon. Editor-in-Chief

P.V.L.N. Srinivasa Rao

Exec. Editor-in Chief

Received: 29 December, 2012.

Vengamma B. Journal of Clinical and Scientific Research: The year that has gone by! J Clin Sci Res 2012;2:1.

\section{REFERENCES}

1. Vengamma B, Srinivasa Rao PVLN. The birth of a journal. J Clin Sci Res 2012;1:1.

2. Medical Council of India. Amendment Notification dated 9th December 2009 of the Postgraduate Medical Education Regulations, 2000. Available at URL: http://www.mciindia.org/RulesandRegulations/ PGMedicalEducationRegulations2000.aspx. Accessed on December 25, 2012. 